\title{
BMJ Open The Canadian survey of health, lifestyle and ageing with multiple sclerosis: methodology and initial results
}

\author{
Michelle Ploughman, ${ }^{1}$ Serge Beaulieu, ${ }^{2}$ Chelsea Harris, ${ }^{1}$ Stephen Hogan, ${ }^{1}$ \\ Olivia J Manning, ${ }^{1}$ Penelope W Alderdice, ${ }^{1}$ John D Fisk, ${ }^{3}$ A Dessa Sadovnick, ${ }^{4}$ \\ Paul O'Connor, ${ }^{5}$ Sarah A Morrow, ${ }^{6}$ Luanne M Metz, ${ }^{7}$ Penelope Smyth, ${ }^{8}$ \\ Nancy Mayo, ${ }^{9}$ Ruth Ann Marrie, ${ }^{10}$ Katherine B Knox, ${ }^{11}$ Mark Stefanelli, ${ }^{12}$ \\ Marshall Godwin ${ }^{13}$
}

To cite: Ploughman $M$, Beaulieu S, Harris C, et al. The Canadian survey of health, lifestyle and ageing with multiple sclerosis: methodology and initial results. BMJ Open 2014;4: e005718. doi:10.1136/ bmjopen-2014-005718

- Prepublication history for this paper is available online. To view these files please visit the journal online (http://dx.doi.org/10.1136/ bmjopen-2014-005718).

Received 20 May 2014 Revised 13 June 2014 Accepted 17 June 2014

CrossMark

For numbered affiliations see end of article.

Correspondence to Dr Michelle Ploughman; mploughm@mun.ca

\section{ABSTRACT}

Objective: People with multiple sclerosis (MS) are living longer so strategies to enhance long-term health are garnering more interest. We aimed to create a profile of ageing with MS in Canada by recruiting 1250 ( $5 \%$ of the Canadian population above 55 years with MS) participants and focusing data collection on health and lifestyle factors, disability, participation and quality of life to determine factors associated with healthy ageing.

Design: National multicentre postal survey.

Setting: Recruitment from Canadian MS clinics, MS Society of Canada chapters and newspaper advertisements.

Participants: People aged 55 years or older with MS symptoms more than 20 years.

Outcome measures: Validated outcome measures and custom-designed questions examining MS disease characteristics, living situation, disability, comorbid conditions, fatigue, health behaviours, mental health, social support, impact of MS and others.

Results: Of the 921 surveys, 743 were returned (80.7\% response rate). Participants (mean age 64.6 \pm 6.2 years) reported living with MS symptoms for an average of $32.9 \pm 9.5$ years and $28.6 \%$ were either wheelchair users or bedridden. There was only $5.4 \%$ missing data and 709 respondents provided optional qualitative information. According to data derived from the 2012 Canadian Community Health Survey of Canadians above 55 years of age, older people with MS from this survey sample are about eight times less likely to be employed full-time. Older people with MS were less likely to engage in regular physical activity (26.7\%) compared with typical older Canadians $(45.2 \%)$. However, they were more likely to abstain from alcohol and smoking.

Conclusions: Despite barriers to participation, we were able to recruit and gather detailed responses (with good data quality) from a large proportion of older Canadians with MS. The data suggest that this sample of older people with MS is less likely to be employed, are less active and more disabled than other older Canadians.

\section{Strengths and limitations of this study}

- This unique cohort provides new insights on ageing with multiple sclerosis (MS). With an average age of about 65 years, our respondents are 10-25 years older than cohorts examined in previous studies of older people with MS.

- Our recruitment methods and a very high survey return rate allowed us to obtain data from about $3 \%$ of our target population.

- With only about $10 \%$ of our sample being employed in any capacity, our results point to a need to understand retirement and employment in ageing with MS.

- The cross-sectional design limits our ability to assess change and the effects of variables on individual outcomes overtime.

- The low sampling of persons in nursing homes and assisted living situations highlights the need for specialised recruitment strategies to study this subset of people living with MS.

\section{INTRODUCTION}

Multiple sclerosis (MS) is a highly unpredictable and heterogeneous autoimmune disease diagnosed between the ages of 18 and 40 years. Affecting women more than men, the cause of MS is unknown, however, research suggests that a combination of environmental factors and genetic predisposition may be the trigger for disease onset. ${ }^{1}$ The number of people with MS above the age of 55 is increasing, possibly due to improved longevity and more effective treatments. ${ }^{2} \mathrm{On}$ the other hand, several authors have shown that smoking ${ }^{3}$ and cardiovascular disease ${ }^{4}$ accelerate disease progression. People with MS are interested in strategies that minimise disability and enhance role participation and quality of life. ${ }^{5}$ The uncertainty surrounding MS progression along with ageing patients with MS warrants the need for investigation 
into potential disease-modifying health behaviours. Older individuals who have lived with MS for many years may provide insight into factors that contribute to living a long and healthy life with MS. ${ }^{6}$

Older people with MS are often excluded from MS research. Studies involving clinical drug trials ${ }^{7}$ and exercise interventions, ${ }^{8}$ in particular, target patients with mild relapsing-remitting disease. Furthermore, because they may not require intensive medical oversight associated with taking disease-modifying drugs, older patients may not attend MS clinics as often as those recently diagnosed. The older MS cohort is also more likely to be disabled and living in an institutional setting, making recruitment challenging. In addition, disabilityrelated impairments such as those affecting vision, cognition and coordination complicate survey and patientreported outcome administration. ${ }^{9}$

To create a profile of ageing with MS in Canada, we developed a national cross-sectional survey, based on previous qualitative research, ${ }^{5}{ }^{6}$ using validated patientreported outcome measures. ${ }^{9}$ We focused on health and lifestyle factors, disability, participation and quality of life, targeting people 55 years of age and older with MS symptoms for 20 or more years. By partnering with major MS clinic registries and MS Society chapters, we hypothesised that we would be able to reach a representative sample of about $5 \%$ of the 'ageing with MS in Canada' cohort.

\section{METHODS}

\section{Participants and sampling}

We targeted Canadians, aged 55 years or older, who had had self-reported MS symptoms for 20 or more years. Prior to recruitment, the study was approved by 11 health research ethics boards in 8 Canadian provinces. Between May 2011 and December 2012, participants were recruited by telephone from lists of eligible MS clinic patients and by public advertising through the MS Society of Canada Research Internet Portal, ${ }^{10}$ local MS Society chapters and their newsletters, and newspaper advertisements. A confirmed diagnosis from a neurologist was available for participants recruited through the MS clinic databases; self-identified participants provided a diagnosis date and neurologist name to confirm their diagnosis. Rather than calculating a sample size, we used an exhaustive sampling technique to obtain a large and representative sample; for example, repeatedly targeting regional newspapers, following up at study sites, making formal and informal contacts with MS Society chapter support groups.

After obtaining consent using a standard script, we mailed participants the questionnaire, with an information sheet, a toll-free telephone helpline number and email address and a prepaid reply envelope. We requested that participants return the completed survey in 2 weeks; non-responders were telephoned for follow-up at 4 weeks. Participants who wished to complete the survey by telephone were encouraged to do so. Each questionnaire was coded to maintain anonymity.

\section{Survey design}

The questionnaire consisted of validated patientreported outcome tools and additional custom-designed questions chosen based on pilot research in a small sample of older people with MS. $^{9}$ We determined during this step that participants preferred a paper rather than online version of the survey as well as larger 14-point font, divided into sections that grouped similar questions together. Respondents were instructed to complete the survey in these sections (chapters) taking a break in between. Since we previously observed confusion with questions involving temporal parameters, questions regarding activity involvement that followed the same timeline (eg, weekly, monthly or yearly) were placed in sequence. To further examine the acceptability of the survey and to minimise skipped or misunderstood items, we asked the first 14 participants (11 returns) to provide feedback on the content, format and response burden. This feedback was integrated into the final version of the questionnaire but the responses were not included in the final data.

To include people with MS in the province of Quebec, Canada, the entire survey including the cover letter was translated into French by one independent professional translator. We also obtained French versions of previously validated tools. Four native French speakers involved in MS research made corrections to the initial translation in sequence. The corrections were then consolidated by a fifth French-speaking MS researcher. The advertisement and consent scripts were translated by a native French-speaking MS researcher and reviewed and corrected by a second researcher.

\section{Survey content}

The final survey consisted of five chapters (table 1) ending with open-response questions for participants to provide additional comments. Where appropriate, we obtained permission from the developers to use previously validated tools.

We used the Multiple Sclerosis Impact Scale (MSIS-29), the Barthel Index and the Co-morbidity Questionnaire to assess health. The MSIS-29 consists of 29 questions: 20 address the physical impact and 9 address the psychological impact of MS generating separate or combined scores as a percentage of 100. Higher scores indicate greater impact of MS. ${ }^{11}$ The MSIS-29 physical component correlates with the Barthel Index (0.71) and the psychological component with EQ-5D (0.68). It is reported to have good responsiveness with large to moderate effect sizes. ${ }^{12}$ The Barthel Index measures function and mobility in activities of daily living (ADL) in 10 areas: feeding, bathing, grooming, dressing, bowel control, bladder control, toileting, transfers, ambulation and stair climbing. ${ }^{13}$ Items are rated in 


\begin{tabular}{|c|c|c|}
\hline Chapter & Domains & Measurement tools \\
\hline \multirow[t]{3}{*}{$\begin{array}{l}\text { You and your MS } \\
\text { (5 pages) }\end{array}$} & Demographics & $\begin{array}{l}\text { Postal code, gender, height, weight, age, finances and } \\
\text { education }\end{array}$ \\
\hline & MS disease characteristics & Symptom onset, time since diagnosis, and type of MS \\
\hline & Environment & Living situation, accessibility and home modifications \\
\hline \multirow[t]{5}{*}{ Your health (6 pages) } & Health-related & Visual analogue scale of perceived health status ${ }^{9}$ \\
\hline & quality of life & Multiple Sclerosis Impact Scale-29 ${ }^{11}$ \\
\hline & Physical health and disability & Barthel Index ${ }^{13}$ \\
\hline & & Co-Morbidity Questionnaire ${ }^{19}$ \\
\hline & Healthcare services & $\begin{array}{l}\text { Use and satisfaction with healthcare services, medications } \\
\text { and complementary/alternative health. }\end{array}$ \\
\hline \multirow[t]{2}{*}{ Your activities (7 pages) } & $\begin{array}{l}\text { Participation and instrumental } \\
\text { activities of daily living }\end{array}$ & $\begin{array}{l}\text { Frenchay Activities Index; }{ }^{21} \text { employment and impact of } \\
\text { fatigue }\end{array}$ \\
\hline & Lifestyle & $\begin{array}{l}\text { Simple Lifestyle Indicator Questionnaire (diet, exercise, } \\
\text { stress, smoking and alcohol) }\end{array}$ \\
\hline \multirow[t]{2}{*}{$\begin{array}{l}\text { Your thoughts and feelings } \\
\text { ( } 8 \text { pages) }\end{array}$} & Mental/cognitive health & $\begin{array}{l}\text { Hospital Anxiety and Depression Scale (HADS) } \\
\text { Resilience Scale }\end{array}$ \\
\hline & & Problems with concentration and memory \\
\hline Your social life (4 pages) & Social support & Personal Resource Questionnaire-2000 30 \\
\hline
\end{tabular}

terms of whether individuals can perform activities independently, with some assistance or are completely dependent, with a total score ranging from 0 (complete assistance required) to 100 (independent). The Barthel Index has been tested in people with $\mathrm{MS}^{14-16}$ and is reliable whether administered by telephone, in-person or by mail $^{17}$ with effect sizes comparable to the Functional Independence Measure $(0.34) .^{18}$ The list of comorbidities used in this survey was adapted from Marrie and Horwitz $^{19} 20$ in consultation with Dr Marrie (personal communication).

We determined the degree of participation in instrumental ADL using the Frenchay Activities Index (FAI) and individual components of lifestyle (exercise, diet, smoking, alcohol and stress) using the Simple Lifestyle Indicator Questionnaire (SLIQ). The FAI assesses the frequency of participation in household chores, social activities, work and leisure for a summed raw score of 15-60; higher score indicating more frequent participation. ${ }^{21}$ The FAI has excellent test-retest reliability as a mailed questionnaire $(0.96)^{22}$ and correlates well with face-to-face interview scores. $^{23}$ The FAI has been mainly used in stroke but has also been used in large MS population studies. ${ }^{24} 25$ The SLIQ was developed to measure the individual components of lifestyle that affect cardiovascular disease. ${ }^{26}$ Initial content and face validity were assessed by the developers among 136 people attending a family practice clinic $^{26}$ and SLIQ scores were highly correlated with those of blinded reviewers $(0.77)$. We were also interested in mental health, coping and social support in ageing with MS. The Hospital Anxiety and Depression Scale (HADS) is a selfassessment scale found to reliably screen for depression and anxiety in patients with $\mathrm{MS}^{27}$ It is divided into an Anxiety subscale (HADS-A) and a Depression subscale (HADS-D) each containing 7 intermingled items scored of
21; higher score indicating greater symptoms. ${ }^{28}$ A threshold score of 8 or higher on HADS subscales had high sensitivity (Depression 90\%, Anxiety 88.5\%) and specificity (Depression $87.3 \%$, Anxiety $80.7 \%$ ) compared with structured interview using DSM-1 criteria among people with MS. $^{27}$ Resilience, the ability to overcome adversity, was measured using the 25 item Resilience Scale. Responses to the test questions range from 1 (disagree) to 7 (agree) and the summed score can be further interpreted as, low resilience $(<120)$, moderate resilience (125-145) and high resilience $(>145)^{29}$ and has been validated in older community-living individuals with high internal consistency reliability $(0.91)^{29}$. The Personal Resource Questionnaire (PRQ-2000) measures social support and consists of 15 statements with which the participant agrees or disagrees based on a seven-point Likert scale; higher scores indicating higher support (eg, I belong to a group in which I feel important: 1, strongly disagree to 7, strongly agree). PRQ-2000 demonstrates good internal consistency (0.87-0.93), adequate construct validity (moderate correlations with anxiety -0.37 , neuroticism -0.28 and extroversion 0.32) and good predictive and construct validity in multiple chronic disease data sets. ${ }^{30}$ Mailed versions have been used in community-living women with chronic health conditions ${ }^{31}$ and adults with $\mathrm{MS}^{32}$

\section{Canadian comparison data}

Comparative data were collected from the Canadian Community Health Survey (CCHS) 2012 version; a national cross-sectional survey that gathers information about health, social and economic status and lifestyle behaviours of the population. Data were extracted from the CCHS database using the University of Toronto Data Library Service (DLS). ${ }^{33}$ A CCHS sample was selected based on age ( $>55$ years). Data were collected from 
CCHS questions that matched questions from our survey (eg, mobility from the Barthel Index and lifestyle from the SLIQ). Outputs (ie, highest level of education, employment status) were analysed using Survey Documentation \& Analysis (SDA) software. ${ }^{34}$ Frequency tables were created for variables of interest.

\section{Data cleaning and imputation}

We custom designed the database application to house project data and minimise error during data imputation. Missing data were imputed using three techniques: (1) deductive imputation, (2) person mean substitution (PMS) and (3) 'hot deck' imputation. ${ }^{35}$ The deductive technique was used to impute missing data when there was sufficient comments and answers to related questions. If less than half of the data were missing on a section, scale or subscale, PMS was used. PMS takes the mean score of the particular participant on that section, scale or subscale and uses the mean as the value for the missing data. If greater than half of the data were missing on a section, scale or subscale, 'hot deck' imputation was used. ${ }^{35}$ This involved taking a value from the 'hot deck' or in other terms, finding another participant of the same gender, age ( \pm 5 years), education level and living in the same province. Hot deck imputation was selected for this study because it is proven to be the most efficient method of data imputation as it is more robust in large samples when compared with other imputation methods. ${ }^{35}$ The exact scores for each question from the substitute participant were imputed for the missing values for the participant of interest. Variables that could not be imputed and remained empty included, from table 1, Demographics (eg, weight, height and finances), MS Disease Characteristics, Environment and Health Care Services.

\section{Data analysis}

Data were analysed using IBM SPSS software V.20. Frequencies and descriptive statistics (mean, SD and data range) were used to determine participant characteristics.

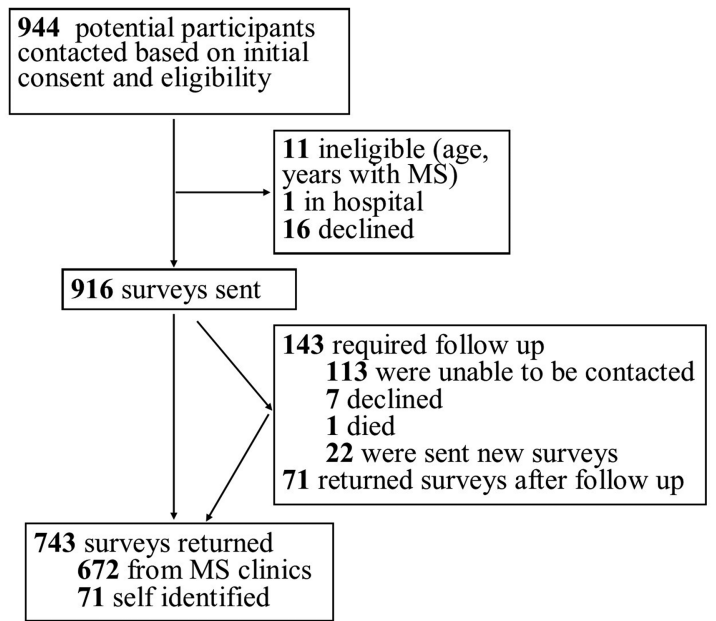

Figure 1 Survey respondents.

\section{RESULTS}

\section{Survey response}

We aimed to recruit 1250 participants for the study and through exhaustive sampling we contacted 921 ( $74 \%$ of target) people with MS who met inclusion criteria. Seven hundred and forty-three participants returned the survey (figure 1; $80.7 \%$ response rate). Survey response by province is illustrated in figure 2 . Of the respondents, $90.4 \% \quad(\mathrm{n}=672)$ were identified through provincial MS clinics while the remaining 71 self-identified by responding to newspaper ads and word of mouth. Forty-five people requested help to complete the survey, and 11 participants asked that the entire survey be completed by phone due to writing or vision difficulties or both. Additional content was provided by 709 participants in the open-ended questions at the end of the survey.

Only 563 of 104763 cells contained missing data $(5.37 \%)$. Almost every survey contained one or two random missing items; in some cases answers to these could be inferred using deductive reasoning (67/104 $763=0.06 \%$ ). We observed no pattern of missing data other than body weight (which we did not impute). The PMS

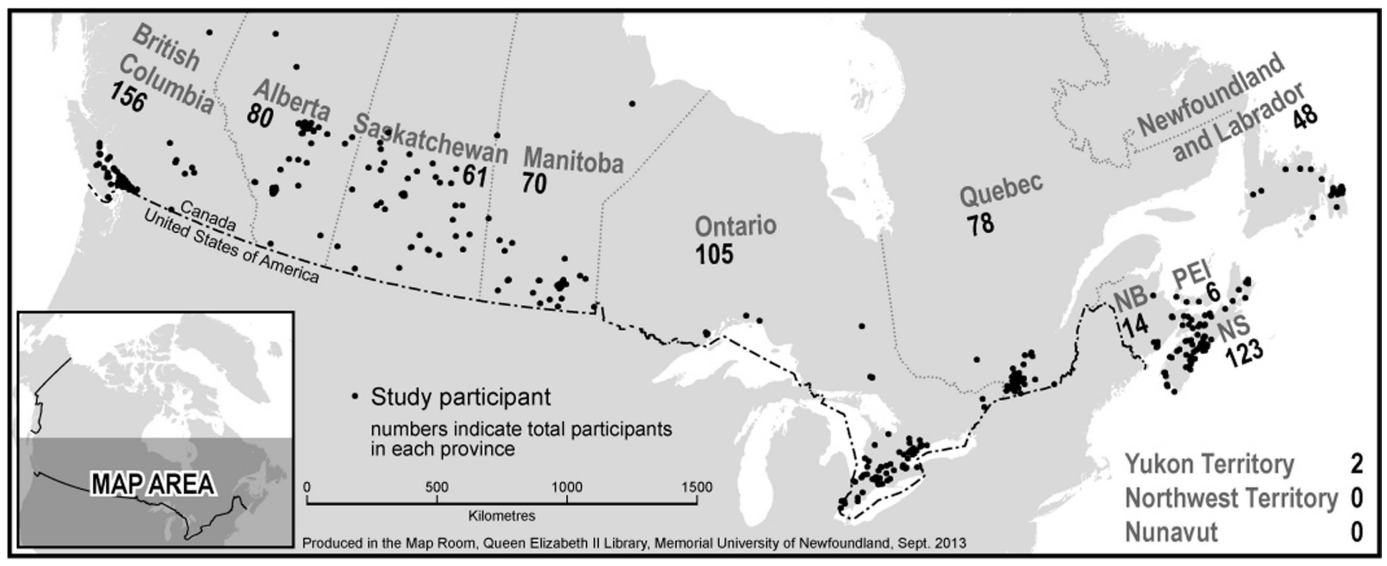

Figure 2 Number of respondents mapped by postal code. 
technique was required for 170 cells $(170 / 94763=0.16 \%)$ and the 'hot deck' technique was required in 14 surveys (324 cells $/ 104763=0.31 \%$ ). Cases of consecutive missing data seemed to be mainly due to pages adhering together resulting in questions being overlooked.

\section{Sample characteristics}

Participants ranged in age from 55 to 88 years with a mean age of 64.6 years $( \pm 6.2)$. They described experiencing MS symptoms for 20-73 years with a mean duration of 32.9 years $( \pm 9.5)$. The respondents reported that the average time from the onset of symptoms to diagnosis by a neurologist was 8.1 years $( \pm 9.4)$ with a range from 0 to 47 years. The number of women outnumbered men 3.5:1 (table 2).

Sixty per cent reported at least 1 year of postsecondary education, and $90 \%$ were either retired or unemployed. About $28 \%$ of the sample $(n=212)$ reported that they were no longer able to walk and either used a wheelchair or were bedridden. The characteristics of the sample are fully described in table 2.

Respondents were categorised by the level of disability based on results of the Barthel Index (figure 3). ${ }^{18}$ We measured activity and participation using the FAI which is divided into the household (domestic) activity, leisure activity and outdoor activity (figure 4). Nearly half $(50.6 \%)$ of the sample frequently participated in household activities but only $13.5 \%$ and $27.9 \%$ reported that they frequently engaged in leisure activities and outdoor activities, respectively.

\begin{tabular}{lc} 
Table 2 Sample characteristics & \\
\hline Characteristic & N (\%) \\
\hline Years with MS symptoms & \\
$20-29$ & $324(43.6)$ \\
$30-39$ & $245(33.0)$ \\
$40-49$ & $135(18.2)$ \\
$50-59$ & $31(4.2)$ \\
60 or more & $7(0.9)$ \\
Initial MS diagnosis & \\
Relapsing-remitting & $386(52.0)$ \\
Primary progressive & $99(13.3)$ \\
Secondary progressive & $65(8.7)$ \\
Progressive-relapsing & $16(2.2)$ \\
Benign & $43(5.8)$ \\
Unknown & $126(17.0)$ \\
Living situation & \\
Living in a private home & $715(96.2)$ \\
Living in an assisted living complex & $16(2.2)$ \\
Living in long-term care & $11(1.5)$ \\
Home care & $146(19.7)$ \\
Equipment & $200(26.9)$ \\
Home modifications & $73(9.8)$ \\
Private insurance (health/disability) & \\
Yes & $393(52.9)$ \\
No & $350(47.1)$ \\
\hline MS, multiple sclerosis. &
\end{tabular}

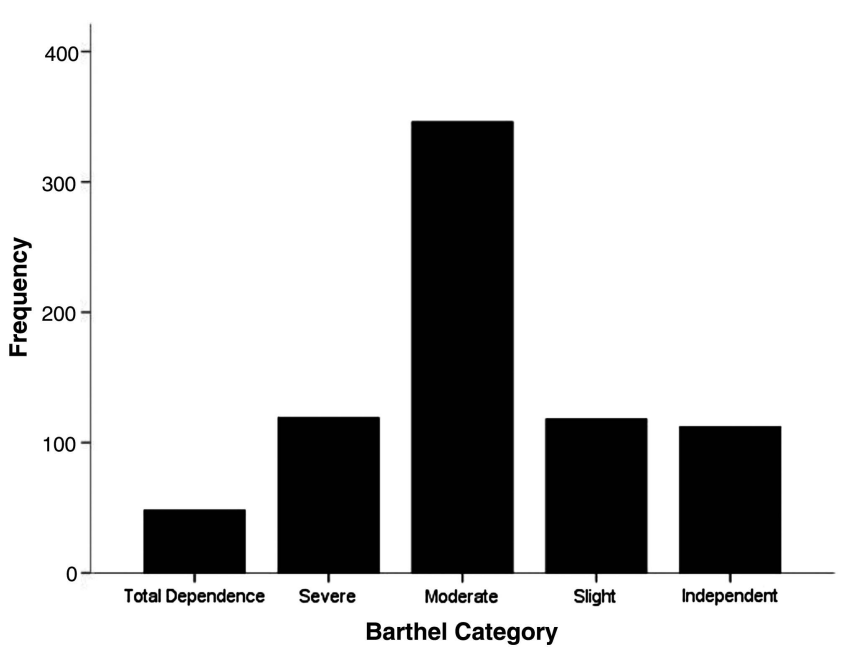

Figure 3 Frequency of Barthel Index score categories: a score of 100 on the Barthel Index suggests that an individual is independently ambulatory, can ascend and descend stairs on their own, is continent and able to perform activities of daily livings without help. Fifteen per cent of this cohort were independent. A Barthel Index score of 91-99 suggests slight dependence (16\%); 61-90 suggests moderate dependence (47\%); 21-60 suggests severe dependence (16\%) and 0-20 represents complete dependence $(7 \%)$.

\section{Older people with MS compared with typical older Canadians}

A comparison sample of older people ( $>55$ years) in Canada was derived from the 2012 Canadian Community Health Survey (CCHS; table 3). CCHS respondents above the age of 55 years primarily lived with their spouse or partner $(52.5 \%)$, with their spouse or partner and children $(11.3 \%)$, or alone $(22.7 \%)$. Only approximately $1 \%$ of this sample was living with their parents. According to data derived from the CCHS, older people with MS from our survey sample had less postsecondary education and were about eight times less likely to be employed full-time. About half of the MS survey sample had major mobility challenges (unable to walk outdoors, use a wheelchair or are bedridden) compared with only $9 \%$ in the CCHS sample. Older people with MS were more likely to engage in physical activity $(69.4 \%)$ compared with typical older Canadians $(45.3 \%)$. They were also more likely to abstain from alcohol and smoking.

\section{DISCUSSION}

The purpose of this national cross-sectional survey was to describe ageing with MS in Canada that would provide the data necessary to determine, in future analysis, the influence of personal, health and environmental factors on quality of life and disability among older people with MS. Incidence and prevalence estimates of MS in Canada are among the highest worldwide ${ }^{36}$ and a shift in peak age prevalence of MS to older ages suggesting that persons with MS in Canada are living longer. ${ }^{2}$ 
Figure 4 Frequency of

Frenchay Activities Index score categories.

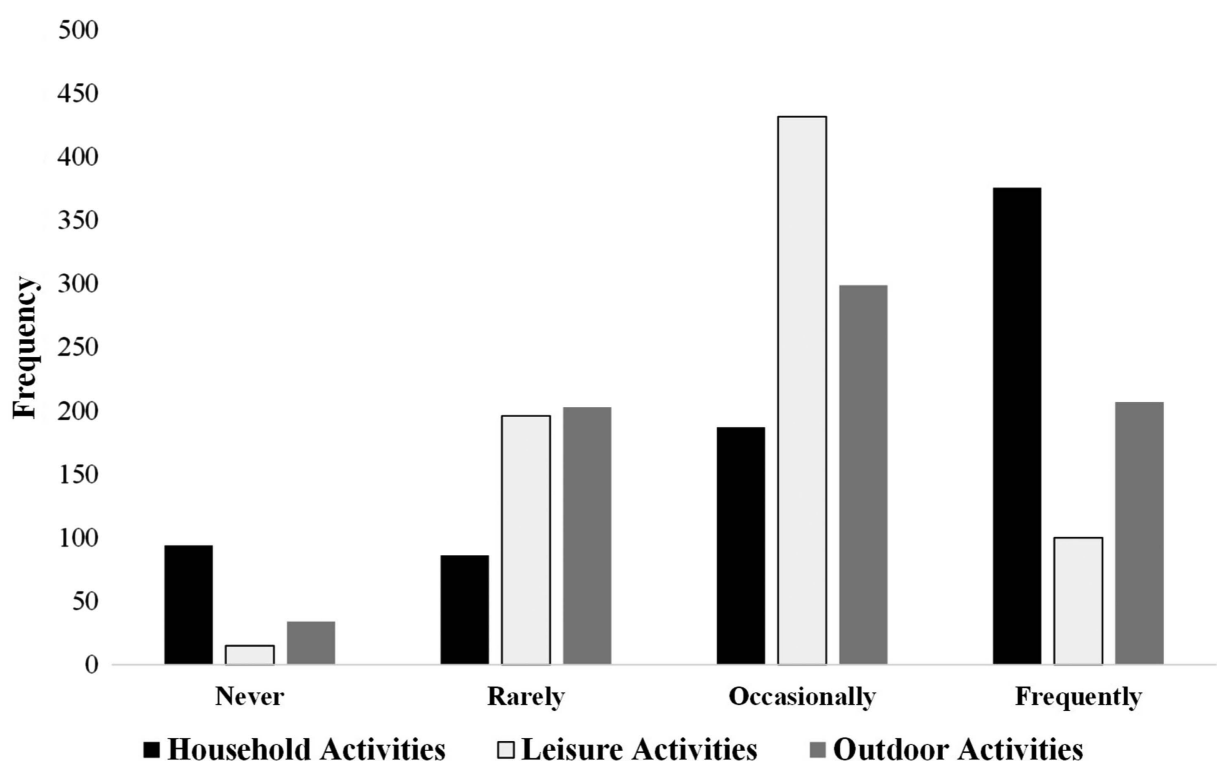

- Household Activities
Interventions to promote successful ageing with MS may take on more importance over the next decade since quality of life and productivity in advanced age is a desired outcome for most. ${ }^{6}$ To the best of our knowledge this is the most comprehensive study focusing on examination of health and lifestyle factors specifically among older persons with MS.

The prevalence of MS in Canada has been estimated to be $240 / 100000 .{ }^{36}$ The CCHS estimates that there are 93535 Canadians living with $\mathrm{MS}^{33}$ and since Statistics Canada estimates that people above 55 years make up about $27.7 \%$ of the population, ${ }^{37}$ there could be approximately 25000 people with MS above 55 years of age. We attempted to contact as many older people with MS as possible and our sample $(n=743)$ likely represents about $3 \%$ of this group, less than our initial $5 \%$ target. Data quality was very good with only $5.4 \%$ missing data and 709 respondents providing optional qualitative data. The high rates of response and completion may be due to prescreening of potential respondents at clinic sites. Only $7.5 \%$ of respondents required assistance from the research team but we were unable to discern survey completion by proxy.

With an average age about 65 years, our respondents are 10-25 years older than cohorts examined in previous studies of older people with $\mathrm{MS}^{38-44}$ Compared with these previous studies, which reported the number of years since MS diagnosis ranging from 8 to 19 years, ${ }^{39} 40$ our participants have been diagnosed with MS for 24.8 $( \pm 10)$ years. Our respondents' level of education aligns with most other studies of people with MS. ${ }^{39-41} 43$ The group is fairly well educated which is not surprising considering characteristics of people who respond to surveys in general. ${ }^{45}$ When compared with the Canadian population, ${ }^{33}$ fewer of our respondents had advanced education including postsecondary degrees and postgraduate degrees. Furthermore, only about $10 \%$ of our sample was employed in any capacity which is substantially lower than other studies of older people with MS. ${ }^{38} 4043$ Since maintaining employment is associated with better quality of life, at least in younger people with $\mathrm{MS},{ }^{43}$ factors associated with employment and retirement as one ages with MS will be an important area of future study. More than a quarter of our cohort were severely disabled (28.6\%); over 10 times that of ageing counterparts in Canada $(2.3 \%)$. They either were restricted to ambulation with a wheelchair or walking with physical assistance indoors or were bedridden; an interesting finding given that most respondents lived in private residences $(96.2 \%)$ without home care, equipment or home modifications. Since only about half of the respondents had private health insurance, it is possible that most people manage at home with few resources outside of the publicly funded health system and the care provided by spouses and children. It was interesting that only a small percentage of survey respondents engaged in leisure or outdoor activity (figure 4). Since the proportion of respondents living in assisted-living and longterm care in this study was small, our sample may not be representative of older people with MS living in these settings.

In terms of lifestyle behaviours, the participants in this study were more physically active and less likely to drink alcohol or smoke compared with their Canadian counterparts. ${ }^{33}$ In large cohorts of people with MS in the UK $(n=895)$ and Belgium $(n=1372)$, healthy lifestyle behaviours are associated with less severe and less rapid disability progression. ${ }^{46}{ }^{47}$ Poor lifestyle behaviours, specifically smoking, have been associated with increased risk of comorbid diseases ${ }^{48}$ and significantly lower HRQOL when compared with people with MS who have never smoked. ${ }^{49}$ Future studies will examine the role of health behaviours and disability in this group of older people with MS.

Although this unique cohort may provide new insights on ageing with MS, there are some study limitations. 
Table 3 Comparison of sample characteristics to others ageing in Canada

\begin{tabular}{|c|c|c|}
\hline Characteristic & Study sample (\%) & CCHS sample (\%) \\
\hline \multicolumn{3}{|l|}{ Age } \\
\hline $55-64$ & $414(55.7)$ & $4671364.6(48.9)$ \\
\hline $65-74$ & $274(36.9)$ & 2891671.1 (30.3) \\
\hline $75+$ & $55(7.4)$ & $1989358.6(20.8)$ \\
\hline \multicolumn{3}{|l|}{ Gender } \\
\hline Males & $166(22.3)$ & $4568522.0(47.8)$ \\
\hline Females & $577(77.7)$ & 4983872.3 (52.2) \\
\hline \multicolumn{3}{|l|}{ Education } \\
\hline Less than high school & 74 (10.0) & 1241946 (15.2) \\
\hline High school & $222(29.9)$ & 1083618 (13.3) \\
\hline $1-2$ year postsecondary & $189(25.4)$ & $408825.2(4.9)$ \\
\hline Complete postgraduate & $258(34.7)$ & $5442586(66.6)$ \\
\hline \multicolumn{3}{|l|}{ Employment status } \\
\hline Retired & $504(67.8)$ & 2878200 (46.3) \\
\hline Unemployed & 166 (22.3) & $302942(4.8)$ \\
\hline Employed full-time & $30(4.0)$ & 2068571 (33.3) \\
\hline Employed part-time & $19(2.6)$ & 698125 (11.2) \\
\hline Employed casual & $24(3.2)$ & 266419 (4.3) \\
\hline \multicolumn{3}{|l|}{ Mobility } \\
\hline Walk independently with or without cane outdoors & $351(47.2)$ & 8004425 (90.9) \\
\hline Walk with cane or help indoors & $180(24.2)$ & $593584(6.7)$ \\
\hline Wheelchair & $161(21.7)$ & \\
\hline Unable to move & $51(6.9)$ & $204744(2.3)$ \\
\hline \multicolumn{3}{|l|}{ Lifestyle } \\
\hline Moderate to vigorous exercise & $193(25.9)$ & $1764305(20.7)$ \\
\hline Some physical activity & $316(42.5)$ & $2083695(24.5)$ \\
\hline No physical activity & $234(31.5)$ & $4652856(54.7)$ \\
\hline No alcohol use & $385(51.8)$ & $2226486(26.3)$ \\
\hline 14 or less drinks per week & $344(46.3)$ & $1242238(14.6)$ \\
\hline$>14$ drinks per week & $14(1.9)$ & $5009245(59)$ \\
\hline Non-smokers & $676(91.0)$ & $7422711(84.4)$ \\
\hline Never smoked & $272(36.6)$ & \\
\hline Quit & $404(54.4)$ & \\
\hline Smokers & $67(9.0)$ & $1372885(15.6)$ \\
\hline
\end{tabular}

The cross-sectional design limits our ability to assess change and the effects of variables on individual outcomes overtime. By nature of the volunteer survey design, our sample may be biased in that active participants were more likely to respond. Even though we provided assistance over the phone, those with significant disability who required assistance may have declined. The low sampling of persons in nursing homes and assisted living situations and those older than 75 years highlights the need for specialised recruitment strategies to study this subset of people living with MS. Although preliminary testing indicated that participants preferred paper, a web-based version may have improved our recruitment. We also have compared our sample with the Canadian Census CCHS sample. The survey questions do not perfectly align so the values are estimates only. A final limitation of the survey was that we selected the Simple Lifestyle Indicator Questionnaire to assess health behaviours because of its short, simple design, so the data collected lacks detail on diet behaviours which will limit future analysis.

\section{Conclusion}

Despite barriers to participation, we were able to recruit and gather detailed responses (with good data quality) from a large proportion of older Canadians with MS. Even with extensive pretesting, national collaboration, exhaustive sampling and high return rates, our recruitment $(n=743)$ was less than our target $(n=1250)$. However, we were able to recruit a large proportion of people who were severely disabled even though only $7.5 \%$ of respondents requested assistance. The data suggest that this sample of older people with MS are less likely to be employed, are more disabled but have more positive health behaviours than other older Canadians.

\section{Author affiliations}

${ }^{1}$ Recovery and Performance Laboratory, Rehabilitation Research Unit, Faculty of Medicine, Memorial University, St. John's, Newfoundland, Canada

${ }^{2}$ Eastern Health Authority, St. John's, Newfoundland, Canada

${ }^{3}$ Department of Psychiatry, Faculty of Medicine, Dalhousie University, Halifax, Nova Scotia, Canada

${ }^{4}$ Department of Medical Genetics and Division of Neurology, Faculty of Medicine, University of British Columbia, Vancouver, British Columbia, Canada 
${ }^{5}$ Department of Neurology, St. Michaels Regional Hospital, Toronto, Ontario, Canada

${ }^{6}$ London Health Science Centre, London, Ontario, Canada

${ }^{7}$ Department of Neurology, University of Alberta, Edmonton, Alberta, Canada

${ }^{8}$ Department of Clinical Neurosciences, University of Calgary, Calgary, Alberta, Canada

${ }^{9}$ Department of Clinical Epidemiology, McGill University, Montreal, Quebec, Canada

${ }^{10}$ Departments of Internal Medicine and Community Health Sciences,

University of Manitoba, Winnipeg, Manitoba, Canada

${ }^{11}$ Department of Physical Medicine and Rehabilitation, College of Medicine,

University of Saskatchewan, Saskatoon, Saskatchewan, Canada

${ }^{12}$ Department of Neurology, Faculty of Medicine, Memorial University, St. John's, Newfoundland, Canada

${ }^{13}$ Primary Health Care Research Unit, Faculty of Medicine, Memorial University, St. John's, Newfoundland, Canada

Acknowledgements The authors specifically acknowledge the work of site coordinators: Trudy Campbell, Heather Rosehart, Amy Cuthbertson, Darren Nickel, Pam Dumont, Madonna de Lemos, Deborah Goldberg, Irene Yee, Nicholas Hall, Maureen Perera, Sarah Williamson, Carolina Moriello and Vanessa Bouchard.

Contributors MP, JDF and MG were involved in the concept development and funding applications. MP, OJM, CH, SH, JDF, ADS, POC, SAM, LMM, PS, NM, RAM and MS were involved in the ethics applications and participant recruitment. MP, OJM, SB, CH, SH and PWA were involved in the data collection, management and analysis. MP, OJM, CH, JDF, ADS, POC, SAM, LMM, PS, NM, RAM, MS and MG were involved in the manuscript preparation and/or review.

Funding This research was supported by a Canadian Institutes of Health Research (CIHR) Post-doctoral Fellowship, a Newfoundland and Labrador Centre for Applied Health Research, Healthy Aging Research Program Project Grant, the Health Care Foundation (Eastern Health Authority) Research Project Grant, and the Physiotherapy Foundation of Canada Alberta Research Award. Support for this project was received from the MS Society of Canada and local chapters; provincial MS clinic neurologists, MS nurses, administrative and research staff; and the Rehabilitation and Continuing Care Program, Eastern Health Authority.

Competing interests MP was supported by a Canadian Institutes for Health Research (Institute of Aging) Postdoctoral Fellowship. Her research was supported by the Newfoundland and Labrador Centre for Applied Health Research, Health Care Foundation, and Physiotherapy Foundation of Canada. $\mathrm{SB}, \mathrm{SH}, \mathrm{PWA}, \mathrm{ADS}$, LMM and NM have no disclosures or conflicts of interest to report. $\mathrm{CH}$ and OJM were supported by end MS Research and Training Network summer studentships. JDF is the director of the end MS Atlantic Regional Research and Training Centre, which is funded by the Multiple Sclerosis Society of Canada. He receives research funding from the Canadian Institutes of Health Research (ClHR) and in the past has received grants, honoraria and consultation fees from Astra Zeneca, Bayer, Biogen-Idec Canada, Heron Evidence Development Limited, Hoffmann-La Roche, MAPI Research Trust, Novartis, Sanofi-Aventis, Serono Canada, and QualityMetric Inc. POC has received consulting fees and/or research support for MS trials from Actelion, Bayer, Biogen Idec, BioMS, Cognosci, Daiichi Sankyo, EMD Serono, Genentech, Genmab, Novartis, Roche, Sanofi Aventis, Teva and Warburg Pincus. SAM has received research support from Biogen Idec and Novartis Canada, and received support for speaking engagement and advisory panels for Bayer, Biogen Idec, EMDSerono and Teva Neurosciences and Novartis Canada. PWS has served on scientific advisory boards for Novartis an EMD Serono. She has received funding for travel to pharmaceutically sponsored events by EMD Serono. She has received honoraria for speaking, facilitating and chairing from Novartis and EMD Serono as well as from the MS Society of Canada. She has received academic research support for medical education research from the Arnold P. Gold Foundation, and the Teaching and Learning Enhancement Fund from the University of Alberta. RAM receives research funding from: Canadian Institutes of Health Research, Multiple Sclerosis Society of Canada, Multiple Sclerosis Scientific Research Foundation, Rx \& D Health Research Foundation, and has conducted clinical trials funded by Sanofi-Aventis. KBK received grant funding from Saskatoon
City Hospital Foundation and MS Society of Canada, educational CME event grant funding from Bayer HealthCare Pharmaceuticals, honoraria/travel grant from Biogen and Teva. She was a member of the CIHR and MS Society of Canada Scientific Expert Working Group on CCSVI and MS. MS has served on advisory boards for Biogen Idec and Novartis and has been provided speaker/ travel support by Teva Neuroscience. His research was supported by Genzyme and Biogen. MG research is funded by the Canadian Institutes of Health Research, Public Health Agency of Canada, Health Canada, and Newfoundland and Labrador Centre for Applied Health Research.

Ethics approval Health Research Ethics Board.

Provenance and peer review Not commissioned; externally peer reviewed.

Data sharing statement No additional data are available.

Open Access This is an Open Access article distributed in accordance with the Creative Commons Attribution Non Commercial (CC BY-NC 4.0) license, which permits others to distribute, remix, adapt, build upon this work noncommercially, and license their derivative works on different terms, provided the original work is properly cited and the use is non-commercial. See: http:// creativecommons.org/licenses/by-nc/4.0/

\section{REFERENCES}

1. Sadovnick AD. Genetic background of multiple sclerosis. Autoimmun Rev 2012;11:163-6.

2. Marrie RA, Yu N, Blanchard J, et al. The rising prevalence and changing age distribution of multiple sclerosis in Manitoba. Neurology 2010;74:465-71.

3. D'Hooghe MB, Haentjens P, Nagels G, et al. Alcohol, coffee, fish, smoking and disease progression in multiple sclerosis. Eur J Neurol 2012;19:616-24.

4. Marrie RA, Rudick R, Horwitz R, et al. Vascular comorbidity is associated with more rapid disability progression in multiple sclerosis. Neurology 2010;74:1041-7.

5. Ploughman M, Austin MW, Murdoch M, et al. Factors influencing healthy aging with multiple sclerosis: a qualitative study. Disabil Rehabil 2012;34:26-33.

6. Ploughman M, Austin MW, Murdoch M, et al. The path to self-management: a qualitative study involving older people with multiple sclerosis. Physiother Can 2012;64:6-17.

7. He D, Guo R, Zhang F, et al. Rituximab for relapsing-remitting multiple sclerosis. Cochrane Database Syst Rev 2013;12 CD009130.

8. Rietberg MB, Brooks D, Uitdehaag BM, et al. Exercise therapy for multiple sclerosis. Cochrane Database Syst Rev 2005;(1): CD003980.

9. Ploughman M, Austin M, Stefanelli M, et al. Applying cognitive debriefing to pre-test patient-reported outcomes in older people with multiple sclerosis. Qual Life Res 2010;19:483-7.

10. Multiple Sclerosis Society of Canada. MS Research Portal. Secondary MS Research Portal 2012. http://msresearch.ca/ (accessed May 2014).

11. Hobart J, Lamping D, Fitzpatrick R, et al. The Multiple Sclerosis Impact Scale (MSIS-29): a new patient-based outcome measure. Brain 2001;124(Pt 5):962-73.

12. Hobart JC, Riazi A, Lamping DL, et al. How responsive is the Multiple Sclerosis Impact Scale (MSIS-29)? A comparison with some other self report scales. J Neurol Neurosurg Psychiatry 2005;76:1539-43.

13. Mahoney FI, Barthel DW. Functional Evaluation: the Barthel Index. Md State Med J 1965;14:61-5.

14. Nicholl L, Hobart J, Dunwoody L, et al. Measuring disability in multiple sclerosis: is the Community Dependency Index an improvement on the Barthel Index? Mult Scler 2004;10:447-50.

15. Cano SJ, O'Connor RJ, Thompson AJ, et al. Exploring disability rating scale responsiveness II: do more response options help? Neurology 2006;67:2056-9.

16. van der Putten JJ, Hobart JC, Freeman JA, et al. Measuring change in disability after inpatient rehabilitation: comparison of the responsiveness of the Barthel index and the Functional Independence Measure. J Neurol Neurosurg Psychiatry 1999;66:480-4.

17. Yeo D, Faleiro R, Lincoln NB. Barthel ADL Index: a comparison of administration methods. Clin Rehabil 1995;9:34-9.

18. Katz PP. Measures of adult general functional status: the Barthel Index, Katz Index of activities of daily living, health assessment questionnaire (HAQ), MACTAR patient preference disability 
questionnaire, and modified health assessment questionnaire (MHAQ). Arthrit Care Res 2003;49:S15-27.

19. Marrie RA, Horwitz RI. Emerging effects of comorbidities on multiple sclerosis. Lancet Neurol 2010;9:820-8.

20. Horton M, Rudick RA, Hara-Cleaver C, et al. Validation of a self-report comorbidity questionnaire for multiple sclerosis. Neuroepidemiology 2010;35:83-90.

21. Wade DT, Legh-Smith J, Langton Hewer R. Social activities after stroke: measurement and natural history using the Frenchay Activities Index. Int Rehabil Med 1985;7:176-81.

22. Turnbull JC, Kersten $\mathrm{P}$, Habib M, et al. Validation of the Frenchay Activities Index in a general population aged 16 years and older. Arch Phys Med Rehabil 2000;81:1034-8.

23. Carter J, Mant F, Mant J, et al. Comparison of postal version of the Frenchay Activities Index with interviewer-administered version for use in people with stroke. Clin Rehabil 1997;11:131-8.

24. Einarsson U, Gottberg K, Fredrikson S, et al. Activities of daily living and social activities in people with multiple sclerosis in Stockholm County. Clin Rehabil 2006;20:543-51.

25. Ytterberg C, Johansson S, Gottberg K, et al. Perceived needs and satisfaction with care in people with multiple sclerosis: a two-year prospective study. BMC Neurol 2008;8:36.

26. Godwin M, Streight S, Dyachuk E, et al. Testing the Simple Lifestyle Indicator Questionnaire: initial psychometric study. Can Fam Physician 2008;54:76-7.

27. Honarmand K, Feinstein A. Validation of the Hospital Anxiety and Depression Scale for use with multiple sclerosis patients. Mult Scler 2009;15:1518-24.

28. Zigmond AS, Snaith RP. The hospital anxiety and depression scale. Acta Psychiatr Scand 1983;67:361-70.

29. Wagnild GM, Young HM. Development and psychometric evaluation of the Resilience Scale. J Nurs Meas 1993;1:165-78.

30. Weinert C. A social support measure: PRQ85. Nurs Res 1987;36:273-7.

31. Weinert C, Cudney S, Hill WG. Rural women, technology, and self-management of chronic illness. Can J Nurs Res 2008;40:114-34.

32. Long KA, Weinert $C$. Descriptions and perceptions of health among rural and urban adults with multiple sclerosis. Res Nurs Health 1992;15:335-42.

33. Statistics Canada. Canadian Community Health Survey: Data Liberation Initiative 2010.

34. Gagne L, Tedds L, Sullivan J, et al. An introduction to the UT/DLS: Microdata analysis subsetting. Secondary An introduction to the UT/ DLS: Microdata analysis subsetting n.d. http://sda.chass.utoronto.ca/ sdaweb/doc/SDAtutorial2008.pdf
35. Hawthorne G, Elliott P. Imputing cross-sectional missing data: comparison of common techniques. Aust N Z J Psychiatry 2005;39:583-90.

36. Evans C, Beland SG, Kulaga S, et al. Incidence and prevalence of multiple sclerosis in the Americas: a systematic review. Neuroepidemiology 2013;40:195-210.

37. Statistics Canada. Population by sex and age group secondary population by sex and age group 2012. http://www.statcan.gc.ca/ tables-tableaux/sum-som/l01/cst01/demo10a-eng.htm

38. Buchanan RJ, Chakravorty BJ, Tyry T, et al. Age-related comparisons of people with multiple sclerosis: demographic, disease, and treatment characteristics. NeuroRehabilitation 2009;25:271-8.

39. Giordano A, Ferrari G, Radice D, et al. Self-assessed health status changes in a community cohort of people with multiple sclerosis: 11 years of follow-up. Eur J Neurol 2013;20:681-8.

40. Asano M, Duquette $\mathrm{P}$, Andersen R, et al. Exercise barriers and preferences among women and men with multiple sclerosis. Disabil Rehabil 2013;35:353-61.

41. Kasser SL, Kosma M. Health beliefs and physical activity behavior in adults with multiple sclerosis. Disabil Health $J$ 2012;5:261-8.

42. Jensen MP, Molton IR, Gertz KJ, et al. Physical activity and depression in middle and older-aged adults with multiple sclerosis. Disabil Health J 2012;5:269-76.

43. Krokavcova M, Nagyova I, van Dijk JP, et al. Mastery, functional disability and perceived health status in patients with multiple sclerosis. Eur J Neurol 2008;15:1237-44.

44. Kayes NM, McPherson KM, Schluter P, et al. Exploring the facilitators and barriers to engagement in physical activity for people with multiple sclerosis. Disabil Rehabil 2011;33:1043-53.

45. Chretien JP, Chu LK, Smith TC, et al. Demographic and occupational predictors of early response to a mailed invitation to enroll in a longitudinal health study. BMC Med Res Methodol 2007;7:6.

46. Manouchehrinia A, Tench CR, Maxted J, et al. Tobacco smoking and disability progression in multiple sclerosis: United Kingdom cohort study. Brain 2013;136(Pt 7):2298-304.

47. D'Hooghe MB, Nagels G, De Keyser J, et al. Self-reported health promotion and disability progression in multiple sclerosis. J Neurol Sci 2013;325:120-6.

48. Marrie RA, Horwitz RI, Cutter G, et al. Smokers with multiple sclerosis are more likely to report comorbid autoimmune diseases. Neuroepidemiology 2011;36:85-90.

49. Weiland TJ, Hadgkiss EJ, Jelinek GA, et al. The association of alcohol consumption and smoking with quality of life, disability and disease activity in an international sample of people with multiple sclerosis. J Neurol Sci 2014;336:211-19. 


\section{Correction}

Ploughman M, Beaulieu S, Harris C, et al. The Canadian survey of health, lifestyle and ageing with multiple sclerosis: methodology and initial results. BMJ Open 2014;4: e005718.

In the 'Results' section of the Abstract it states

that 'Older people with MS were less likely to engage in regular physical activity (26.7\%) compared with typical older Canadians (45.2\%). However, they were more likely to abstain from alcohol and smoking.' This is incorrect and should read the same as within the article text and tables-that is, 'Older people with MS were more likely to engage in regular physical activity (69.4\%) compared with typical older Canadians (45.3\%). They were also more likely to abstain from alcohol and smoking.'

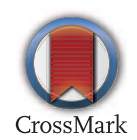

BMJ Open 2015;5:e005718. doi:10.1136/bmjopen-2014-005718corr1 